Article

\title{
Comparative Analysis of Transcriptomes to Identify Genes Associated with Fruit Size in the Early Stage of Fruit Development in Pyrus pyrifolia
}

\author{
Shuang Jiang ${ }^{\dagger}$, Haishan An ${ }^{\dagger}$, Jun Luo *, Xiaoqing Wang, Chunhui Shi and Fanjie Xu \\ Forestry and Pomology Research Institute, Shanghai Key Lab of Protected Horticultural Technology, \\ Shanghai Academy of Agricultural Sciences, 1000 Jinqi Road, Fengxian District, Shanghai 201403, China; \\ jiangshuang@saas.sh.cn (S.J.); anhaishan530@163.com (H.A.); wxqshirley666@163.com (X.W.); \\ shichunhui6666@163.com (C.S.); funjx@163.com (F.X.) \\ * Correspondence: pear_luo@126.com or luojun@saas.sh.cn \\ † These authors contributed equally to this work.
}

Received: 25 June 2018; Accepted: 7 August 2018; Published: 9 August 2018

\begin{abstract}
Pear (Pyrus L.) is an important commercial fruit in the world. The fruit size is one of the important characters in fruit quality. The previous research reported that the fruit size of pear was mainly caused by the number of cell in about 40 days after blossom (DAB) in nature. However, studies about the mechanisms underlying cell division in young fruit development are very limited in pear. Two pear accessions codenamed 'GH59B' with big fruit and 'GH81S' with small fruit in three stages were sampled and the RNA-seq high-throughput sequencing was used to evaluate changes of gene transcription levels in the early stage of fruit development. The difference of cell size among two samples was little in $40 \mathrm{DAB}$, implying that the difference of the fruit size was caused by the number of the cell. More than 274,517,982 high quality reads from six libraries of fruit development were sequenced. A total of 797 differentially expressed genes (DEGs) were identified. Three cytokinin dehydrogenase genes and two gibberellin 2-beta-dioxygenase gene were identified in the Kyoto Encyclopedia of Genes and Genomes (KEGG) pathways related to zeatin and gibberellin. Their expression was upregulated at $20 \mathrm{DAB}$ in ' $\mathrm{GH} 81 \mathrm{~S}^{\prime}$ and at $30 \mathrm{DAB}$ in 'GH59B', suggesting that the small fruit size might be related to the early degradation of cytokinin and gibberellin inducing a short period of cell division. A total of 38 DEGs of transcription factors were found and 23 DEGs including $N A C, E R F$ and $b H L H$ transcription factors were highly related with cytokinin dehydrogenase and gibberellin dioxygenase genes. Altogether, the results of the present study provide information from a comprehensive gene expression analysis and insight into the molecular mechanism underlying the difference of fruit size in Pyrus pyrifolia.
\end{abstract}

Keywords: fruit size; Pyrus; cell division; development; transcript

\section{Introduction}

Fruit size is not only a very important appearance quality but also strongly associated with the commercial value. The environmental factors, chemicals and internal heredity could regulate fruit size. For example, thinning and adequate nutrition can increase fruit size [1,2]. Benzyladenine, forchlorfenuron (CPPU) and gibberellin treatments could increase fruit weight and diameter $[3,4]$. The genetic background could also influence fruit size. Under the same growth conditions, some pear cultivars in Pyrus pyrifolia have large fruits (such as 'Housui') and some wild pear accessions in P. betulaefolia have small fruits. Fruit size is determined by the number of cells and cell size during fruit development. In apple, fruit size was positively correlated with cortex cell number [5]. In melon, that fruit size is also determined by the amount of cell proliferation in the early stage of fruit development [6]. 
In sweet cherry, the average cell numbers were significantly different between cultivars with big and small fruit, indicating that flesh cell number is the major contributor to differences in fruit size between cultivars [7]. These reports indicated the difference in cell numbers affecting fruit size. Some other studies have shown that both of cell number and cell size induce fruit size difference. In Malus floribunda, whose fruit size is one of the smallest among Malus, exhibited absence of cell proliferation throughout fruit ontogeny. Furthermore, the rate of cell enlargement, which was almost uniform until the mature stage in other species, slowed down from about 45 days after full blossom, resulting in a cell size approximately half that of the other cultivars [8]. The carpel/floral-tube size was enhanced in 'Grand Gala', which was a large fruit size spontaneous mutant of 'Gala'. It was associated with cell number and size [9].

The growth curve of the pear is close to the $S$ type. The cell proliferation increased significantly in the 3-4 weeks after pollination, which was like apple [10]. The growth of the fruit was mainly manifested by the increase in the number of cells in this period. The late maturing varieties have larger fruit types than those of early maturing varieties in Japanese pears and the difference in fruit size among varieties was mainly determined by the number of cells, not the size of the cells [11]. The late-ripening varieties were often larger than those of early maturing varieties. The reason is mainly related to the extension stage of cell division.

A lot of genes were related to cell number and cell size [12]. In tomato, two developmental timing of genes of fruit weight 2.2 (FW2.2) and FASCIATED known to affect tomato fruit size and shape were reported [13]. The gene $F W 2.2$ regulates the size of fruit by regulating the proliferation of early growth and development of the fruit $[14,15]$. The gene FASCIATED encodes a YABBY-like transcription factor, which regulates the size of tomato fruit by regulating the number of carpels [16]. Silencing of the DELLA1 gene in tomato produced very similar vegetative and reproductive phenotypes to those described for gibberellin 20-beta-dioxygenase 1 (GA20ox1) overexpressing plants [17], as fruits were facultative parthenocarpic, smaller in size and elongated in shape. Some other genes promote cell proliferation and cell enlargement to regulate the growth and size of plant tissue [18,19]. In Arabidopsis thaliana, the transcription factor AINTEGUMENTA (ANT) can affect the end of cell proliferation and it is a key gene to regulate the size of tissue [20]. The auxin-inducible gene ARGOS can regulate the size of the lateral tissue and prolong the expression of ANT [21]. KLUH, a cytochrome P450 gene, participates in the formation of the RNA polymerase complex. The overexpression of $K L U H$ leads to larger organs with more cells [22]. The JAGGED gene encodes a zinc finger protein that promotes leaf tissue development [23]. BIG BROTHER, an E3 ubiquitin ligase, is a repressor of plant organ growth and alter organ size [24]. In addition. The proliferation of plant cells is also regulated by the cell cycle. In Arabidopsis, the cell cycle is regulated by cyclin, cyclin dependent kinase (CDKs), cyclin kinase inhibitor (ICK/KRPs) and E2F transcription factor [25]. The overexpression of CDKB1;1 can reduce the number of cells [26] and a small amount of cell cycle protein kinase inhibitor KRP2 can reduce cell production rate, decrease leaf area and change leaf shape [27].

In P. pyrifolia, the fruit size was related to the cell number. The cell division occurred in the early stage in the development of fruit. Therefore, studies on the variation of fruit size in young fruit stage might be more helpful for understanding different fruit size in Pyrus. In this study, we selected two pear accessions with different fruit size in hybrid F1 generation from 'Gold Nijiss Qiki' and 'Housui' and collected samples of young fruits at 10, 20 and 30 days after blossom. The transcriptome was investigated in fruit development to reveal the molecular mechanism of cell division. We sequenced six cDNA libraries using Illumina deep-sequencing technology. The gene expression profiles will provide valuable resources for the identification of pear genes involved in fruit size difference. 


\section{Results}

\subsection{The Fruit Weight and Histological Sections of 'GH59B' and 'GH81S' in Forty Days after Blossom}

The fruit weight of 'GH59B' and 'GH81S' were measured at 10, 20, 30, 40 and 130 DAB. The weight of both samples was increased in the development of fruit (Figure 1a). At 10 DAB, the weight between 'GH59B' and 'GH81S' had no obvious difference. The differences were appeared before 20 DAB, right after $10 \mathrm{DAB}$ and expanded gradually. The mature fruit weight of 'GH59B' and 'GH81S' were $368.4 \mathrm{~g}$ and $75.5 \mathrm{~g}$ at $130 \mathrm{DAB}$, respectively (Figure $1 \mathrm{~b}$ ). By visual inspection, the anatomical structures of the pulp cell showed little difference in the cell size of two samples (Figure 1c). The cross-section area of 'GH59B' and 'GH81S' were calculated. The cell size was increased largely in both of two samples in all stage of fruit development (Figure 2). The cell size has grown about twice between 10 DAB and 20 DAB. The median of cell size in 'GH81S' was larger than in 'GH59B' in early three stage of fruit development. At 40 DAB, the cell size of 'GH59B' was larger than 'GH81S.' The difference in cell size among the two samples was little. Therefore, we implied that the difference of the fruit size was caused by the number of cell in early fruit development. At $130 \mathrm{DAB}$, the cell size varied largely in 'GH59B' and 'GH81S.' The cross-section area of the cell was difficult to calculate. Some very large cells were found (Figure 1c), which might be related with the subsequent rapid fruit growth.

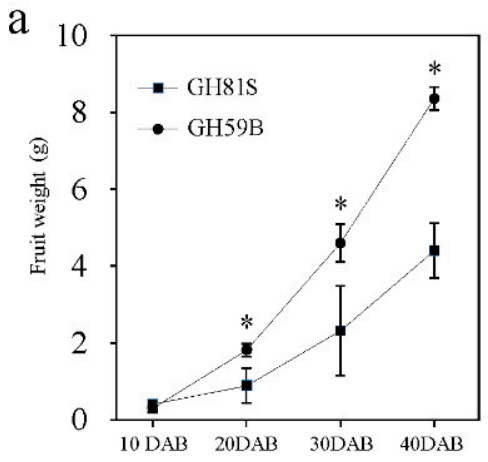

$\mathrm{C}$

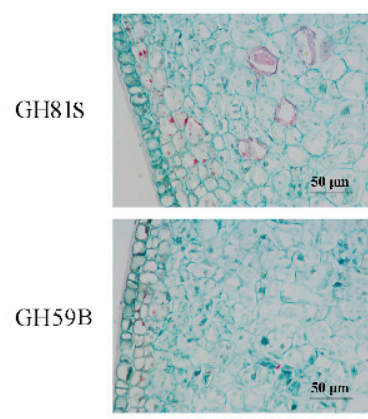

$10 \mathrm{DAB}$

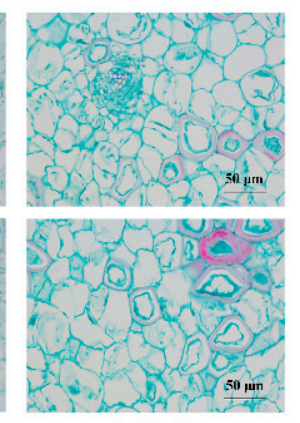

$20 \mathrm{DAB}$
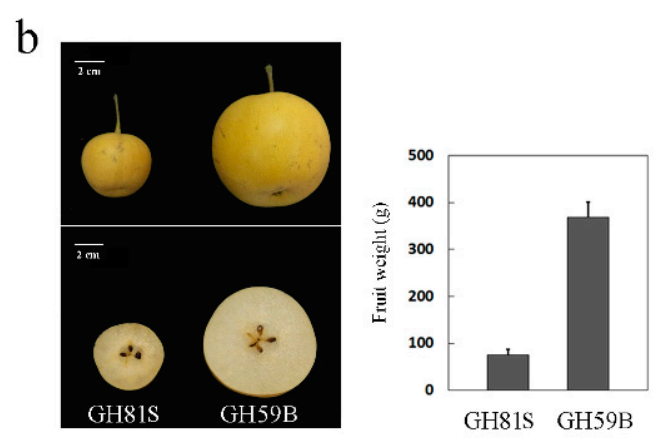

Mature fruit (130 DAB)

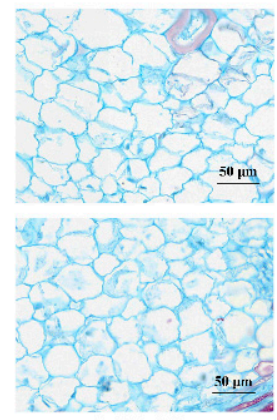

$30 \mathrm{DAB}$

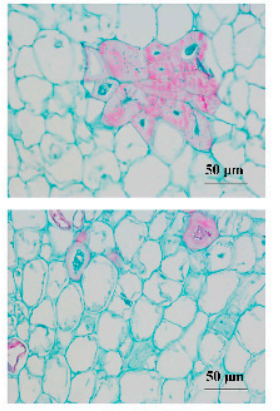

$40 \mathrm{DAB}$

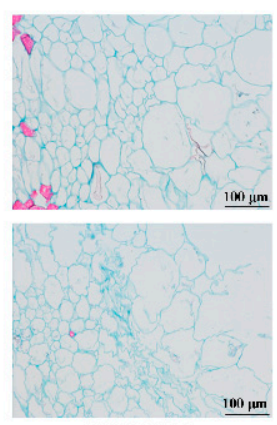

$130 \mathrm{DAB}$

Figure 1. Development of the fruit of 'GH81S' and 'GH59B' in 40 days after blossom. (a) Fruit weight. The asterisks represent significant differences determined by Student's $t$ test at $p<0.05$. (b) The mature fruit, (c) Histological sections of young fruit. 


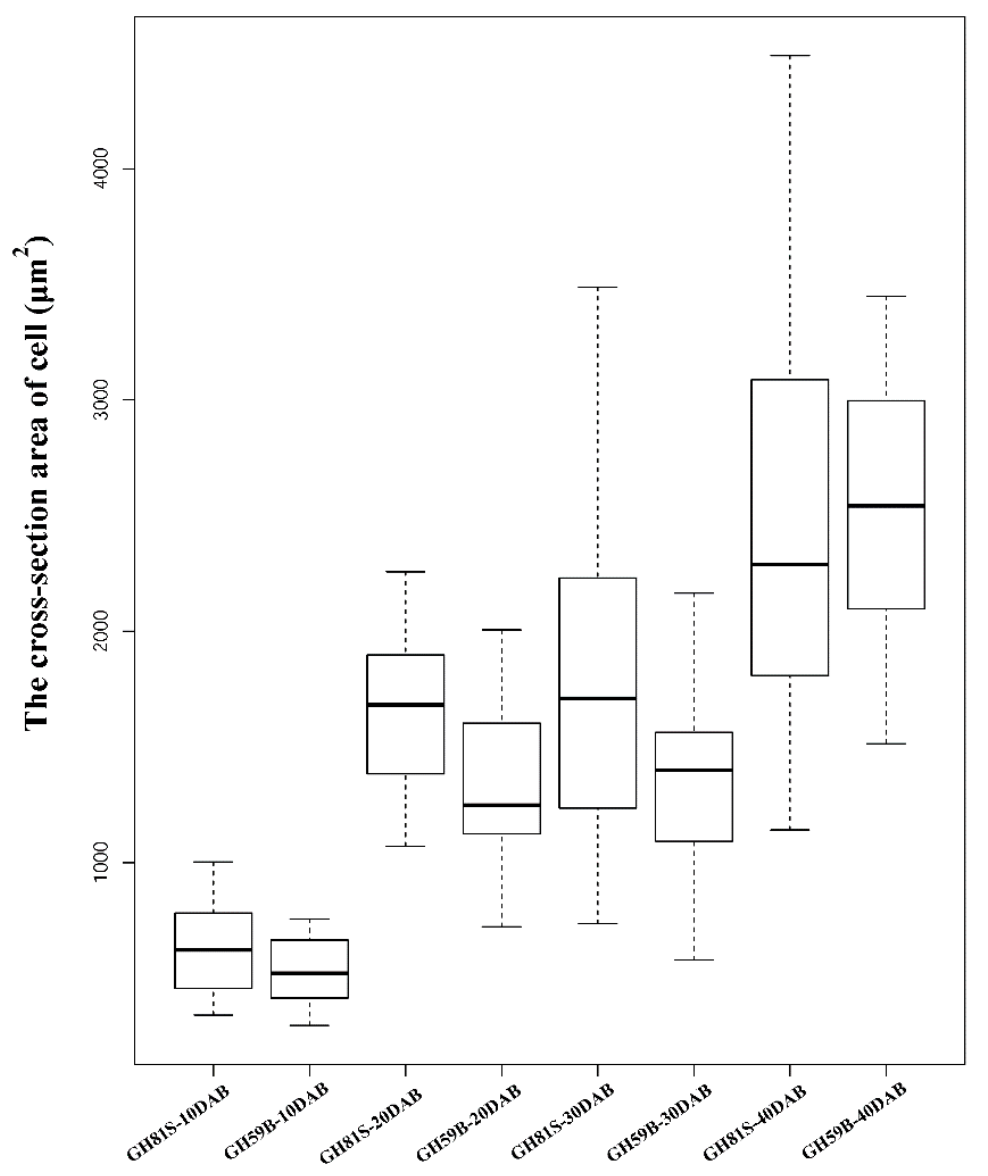

Figure 2. The cross-section area of cell size of 'GH81S' and 'GH59B' in 40 days after blossom.

\subsection{Library Construction, Sequencing and Differentially Expressed Genes (DEGs) Identified Using RNA-Seq}

The fruit of 'GH59B' and 'GH81S' were sampled at 10, 20 and 30 DAB and were subjected to total RNA extraction and an RNA-seq analysis. High-throughput sequencing generated 47.46-52.40 million (M) $150 \mathrm{bp}$ paired-end reads from each library (Table 1). After a stringent quality filtering process, $41.18 \mathrm{~Gb}$ of clean data $(90.86 \%$ of the raw data) were obtained, with a Q30 percentage $\geq 94 \%$. The counts of clean reads per library ranged from 43.56 to $46.79 \mathrm{M}$ (Table 1 ). Reads were mapped to the reference genome sequence of Chinese white pear 'Dangshansuli' (Pyrus pyrifolia White pear group) [28]. The percentages of mapped reads were similar among the 6 libraries (68.7-70.4\%) (Table 1).

Table 1. Statistics of the reads in the present study.

\begin{tabular}{cccccc}
\hline Samples & Raw Reads & Total Clean Reads & Total Mapped Reads & Q20 & Q30 \\
\hline GH81S-10 DAB & $47,463,332$ & $43,555,990$ & $70.40 \%$ & $98.31 \%$ & $95.38 \%$ \\
GH81S-20 DAB & $50,756,314$ & $46,213,290$ & $69.20 \%$ & $98.25 \%$ & $95.26 \%$ \\
GH81S-30 DAB & $52,395,106$ & $46,794,198$ & $68.70 \%$ & $98.40 \%$ & $95.55 \%$ \\
GH59B-10 DAB & $50,756,688$ & $46,472,938$ & $69.80 \%$ & $98.35 \%$ & $95.47 \%$ \\
GH59B-20 DAB & $50,018,632$ & $45,642,660$ & $69.70 \%$ & $98.27 \%$ & $95.31 \%$ \\
GH59B-30 DAB & $50,757,620$ & $45,838,906$ & $69.00 \%$ & $98.10 \%$ & $94.89 \%$ \\
\hline
\end{tabular}

The genes with reads per kilobase of transcript per million mapped reads (RPKM) value of six samples were calculated. Differences in gene expression in six samples were examined using the threshold of FDR $\leq 0.001$ and $\mid \log 2$ Ratio $\mid \geq 1$. The DEGs were identified by pairwise comparisons of the libraries from 'GH59B' and 'GH81S'; that is, GH81S-10DAB vs. GH59B-10DAB 
(Figure 3a). For each stage; 393 DEGs were detected at 10 DAB. At 20 DAB; 463 DEGs were identified; which is more than in $10 \mathrm{DAB}$ and $30 \mathrm{DAB}$ (368 DEGs) (Figure 3b). After merging the DEGs in three stages; 797 DEGs were found in the early fruit development in pear; which was investigated further (Table S1). Eight genes were selected to have their transcript levels measured by Q-PCR; including Zeatin O-glucosyltransferase 1 (ZOG1), cytokinin dehydrogenase 6 (CKX6), cytokinin dehydrogenase 7 (CKX7), Gibberellin 2-beta-dioxygenase 1 (GA2OX1), 1-aminocyclopropane-1-carboxylate synthase $(A C S), 1$-aminocyclopropane-1-carboxylate oxidase (ACO), NAC25 transcription factor; and WUSCHEL-related homeobox 1 (WOX1). The differential expression trends detected by Q-PCR and RNA-seq were largely consistent (Figure 4), indicating the reliability of the RNA-seq results.

a

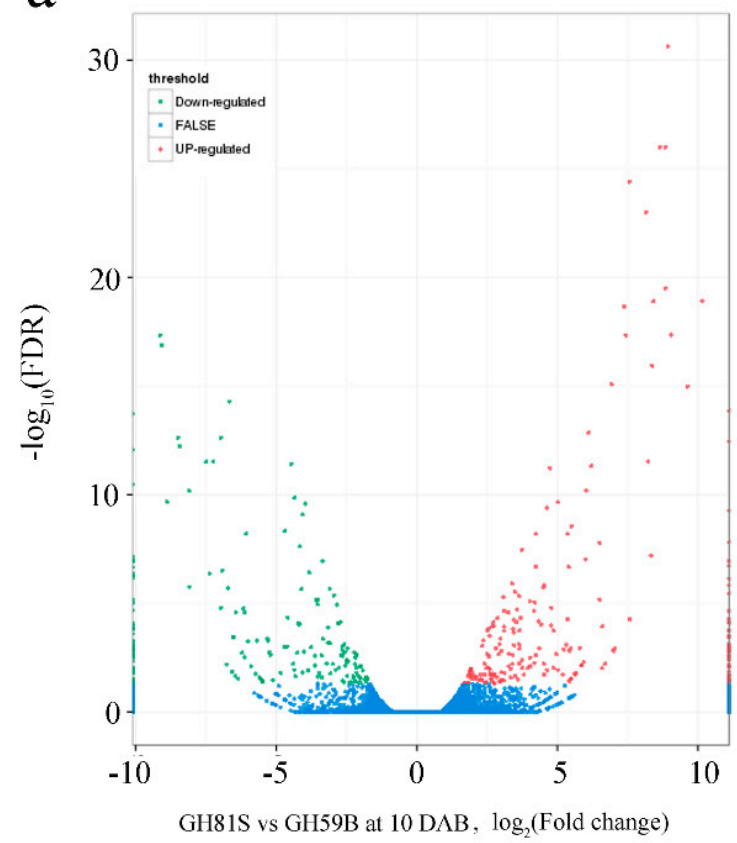

b

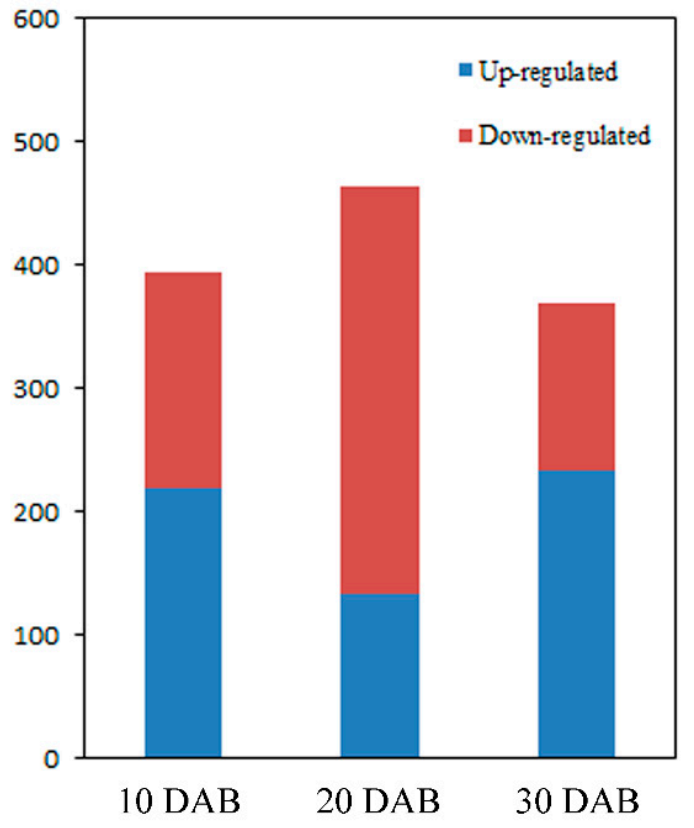

Figure 3. Statistics of differently expressed genes. (a) Significantly up- or downregulated genes using the threshold of FDR $\leq 0.001$ and $\log _{2}$ Ratio $\geq 1$ in GH81S vs. GH59B at 10 DAB. (b) Number of upregulated and downregulated transcripts in three stage of fruit development.

\subsection{DEGs Involved in the KEGG Pathways Related to Zeatin and Gibberellin}

All DEGs were mapped with the KEGG database to identify the significant enrichment of pathways. A total of 82,89 and 80 pathways were found at 10, 20 and 30 DAB respectively. The size variety of 'GH59B' and 'GH81S' was speculated to be caused by the cell number and the cell number in fruit development was related with zeatin and gibberellin in the previous research. The KEGG pathways of zeatin biosynthesis (ko00908), gibberellin related diterpenoid biosynthesis (ko00904) and the plant hormone signal transduction of zeatin and gibberellin (ko04075) were investigated to scan the putative key genes. In all isolated DEGs, twenty-seven DEGs were found in three KEGG pathways (Table S2). Twelve DEGs were related to zeatin, of which eight DEGs in biosynthesis and four DEGs in the signal transduction were found respectively. In zeatin biosynthesis pathway, two genes of cytokinin dehydrogenase (CKX7, Pbr024972.1; CKX6, Pbr009698.1) and one gene of Zeatin O-glucosyltransferase 1 (ZOG1, Pbr002045.1) were isolated. Both of them were regarded as a main negative regulator in cytokinin metabolism in plants, irreversibly degrades cytokinins into adenine/adenosine moiety. In 'GH81S' with small fruits, these genes were upregulated at 20 DAB but they were upregulated at $30 \mathrm{DAB}$ in 'GH59B' with big fruits (Figure 4). At 10 and $40 \mathrm{DAB}$, these genes maintained the low 
level of expression. Nine DEGs in diterpenoid biosynthesis and six DEGs in corresponding signal transduction were found. In gibberellin biosynthesis, Gibberellin 2-beta-dioxygenase 1 (GA2OX1) used bioactive GAs and their immediate precursors and converted them to inactivity forms. In our result, two genes of GA2OX1 (Pbr025274.1) and GA2OX8 (Pbr009976.1) were isolated. Their expression was like cytokinin dehydrogenase genes. They were upregulated at $20 \mathrm{DAB}$ in 'GH81S' and at $30 \mathrm{DAB}$ in 'GH59B'.

a
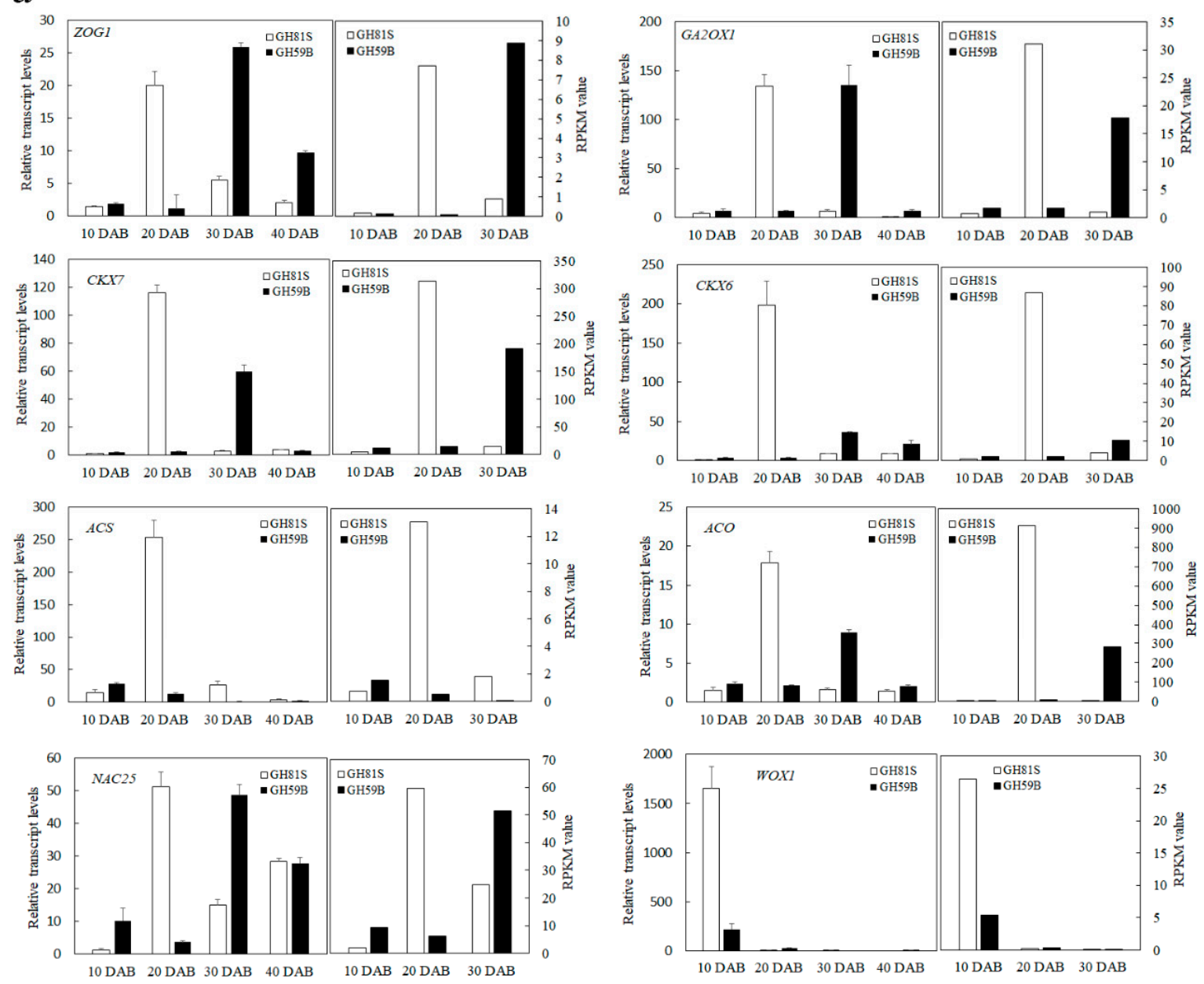

b

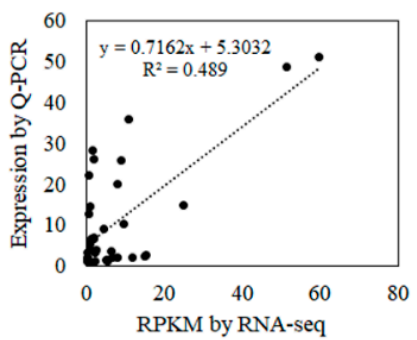

Figure 4. The expression of eight genes in fruit of 'GH81S' and 'GH59B.' (a) Q-PCR validation of differential gene expression. (b) Coefficient analysis between the gene expression ratios obtained from RNA-seq and Q-PCR data.

\subsection{The Annotation of Structural Genes Related to Fruit Development}

In all isolated DEGs, function unknown and low expression genes were removed firstly and then the genes not related to fruit development were deleted, such as resistance protein and 
leucine-rich repeat receptor (Table S1). Structural genes and transcription factors were analyzed separately. Twenty-four structural DEGs were identified (Table S3). Three genes (Pbr009641.1, Pbr016511.2 and Pbr040203.1) were annotated to xyloglucan endotransglucosylase (XET), which was induced by brassinosteroid and improved cell division. Pbr016511.2 was upregulated in all stage in 'GH59B' and Pbr009641.1 was upregulated at 20 DAB in 'GH59B'. Pbr040203.1 was upregulated at 20 DAB in 'GH81S' and 30 DAB in 'GH59B.' Four genes were related to the pathway of ethylene biosynthesis and promote the synthesis of ethylene. Pbr002233.1 was annotated to 1-aminocyclopropane-1-carboxylate synthase (ACS). Three genes (Pbr023059.1, Pbr031954.1 and Pbr015589.1) were annotated to 1-aminocyclopropane-1-carboxylate oxidase (ACO). Except for Pbr015589.1, the expression of the other three genes were significantly upregulated at $20 \mathrm{DAB}$ in 'GH81S' and at 30 DAB in 'GH59B,' which was similar with cytokinin dehydrogenase genes. One gene of WUSCHEL-related homeobox (WOX1) was isolated, which plays important roles in the maintenance and proliferation of the stem cell niche in the shoot apical meristem. It was up-regulated at $10 \mathrm{DAB}$ in both of 'GH81S' and 'GH59B' and the gene expression in 'GH81S' was higher than in 'GH59B'. Two genes (Pbr027542.1 and Pbr016230.1) were related to the auxin-repressed protein. Their expression was up-regulated at 10 and 30 DAB in 'GH59B.' Fourteen DEGs were annotated to the cytochrome P450. Pbr009519.1 (CYP90A1) and Pbr030002.1 (CYP734A1) were involved in brassinosteroids inactivation and regulation of BRs homeostasis. Their expression was upregulated at $20 \mathrm{DAB}$ in 'GH81S' and upregulate at $30 \mathrm{DAB}$ in 'GH59B.' The gene of CYP714 encodes gibberellin 13-oxidases that reduce gibberellin activity. Two genes of CYP714A1 (Pbr002890.1) and CYP714C2 (Pbr017314.1) were isolated and they were upregulated at 20 and 30 DAB in 'GH81S,' which might inhibit the cell growth. One gene of CYP78A9 (Pbr018401.1) was identified, which was related to induce large and seedless fruit in Arabidopsis. The expression of CYP78A9 was upregulated at 10 and $20 \mathrm{DAB}$ in 'GH59B' but $30 \mathrm{DAB}$ in 'GH81S'. The function of the remaining nine genes from cytochrome P450 was unknown, which were not further analyzed.

\subsection{The DEGs Related to Transcription Factors}

Transcription factors play important roles in the regulatory network. A total of 38 DEGs were annotated to transcription factors (Table S4). All DEGs were clustered with cytokinin dehydrogenase and gibberellin dioxygenase genes to identify the putative upstream regulation genes (Figure 5). Group1 including 23 DEGs and Group 2 including 15 DEGs were clustered separately (Table S4). The expression of genes in Group 1 was highly related to cytokinin dehydrogenase and gibberellin dioxygenase genes. Nine genes were annotated to the NAC transcription factor, which involves plant growth and development, hormone regulation and response to the environmental stress. Four genes were ethylene responsive transcription factor $(E R F)$. This factor regulates various physiological processes of plant growth and development. Lager number of members were found in NAC and ERF families implying that these families might participate in the development of fruit and determine the size of the fruit. Three MYB21 and two bHLH113 transcription factor were isolated. The remaining five transcription factors were annotated to WRKY75, GLK2, UNE10, TGA7 and CYCLOIDEA. These transcription factors were rarely reported to regulate the fruit development.

\subsection{Protein Protein Interaction (PPI) Network Analysis}

PPI network could identify putative direct physical interactions and indirect functional correlations between two proteins. All 797 DEGs were mapped with genes in PPI network from Arabidopsis in STRING database. A lot of networks in three stages were found and networks including genes with large differences between 'GH81S' and 'GH59B' were showed in Figure S1. Five genes of ZOG1, CKX6, CKX7, GA2OX1 and GA2OX8 in the previous result were searched the PPI network in all 797 DEGs. Only CKX7 (Pbr024972.1) was found in a network and interacted with eight genes (Figure 6). One gene was annotated to $A C S$, suggesting that cytokinin dehydrogenase was related with ethylene synthesis. Although the $A C O$, one of rate-limiting enzyme of the ethylene biosynthetic pathway, was 
not found in the network with $C K X$, the expression profile of $A C O$ was also consistent with $A C S$ and $C K X$. Four genes were found to be related with $A C S$ and $C K X 7$ and were annotated to aldehyde dehydrogenase 3 ( $A L D H 3$, Pbr022147.1), NAD-dependent malic enzyme (ME, Pbr020609.1), probable aminotransferase TAT2 (Pbr038270.1) and proline transporter 1 (PROT1, Pbr009467.1). The function of these four genes in fruit development was still unclear. The remaining two genes were glycine cleavage system H protein 3 (GCS, Pbr023079.1) and 6-phosphofructokinase 2 (PFK2, Pbr000007.1), which were not related with fruit development. In the network of ACS, 16 DEGs were found (Figure 6). Most of them were related to metabolic pathways and their function should be further analysis.

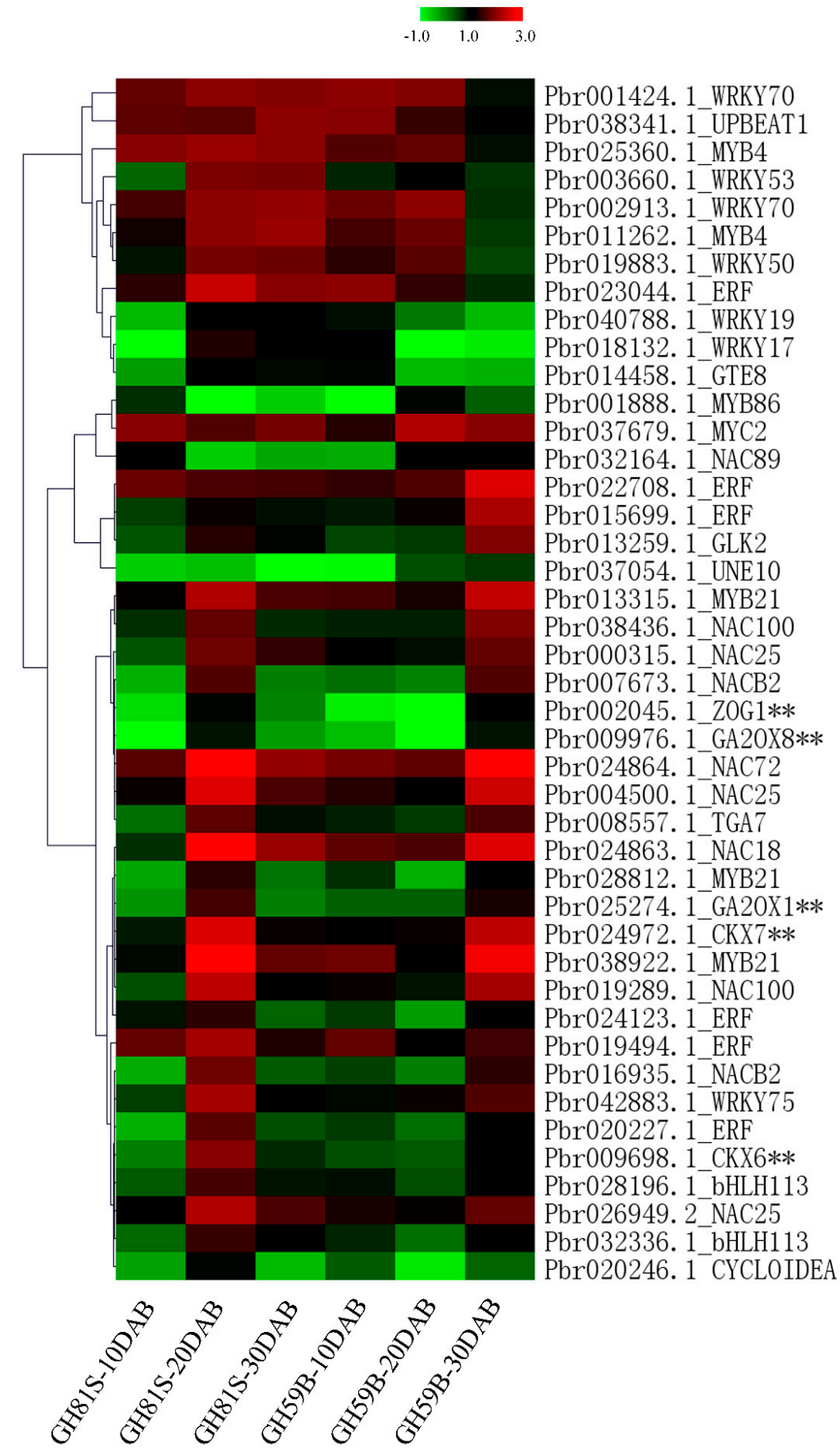

Figure 5. Heatmap of the expression of transcription factors. 


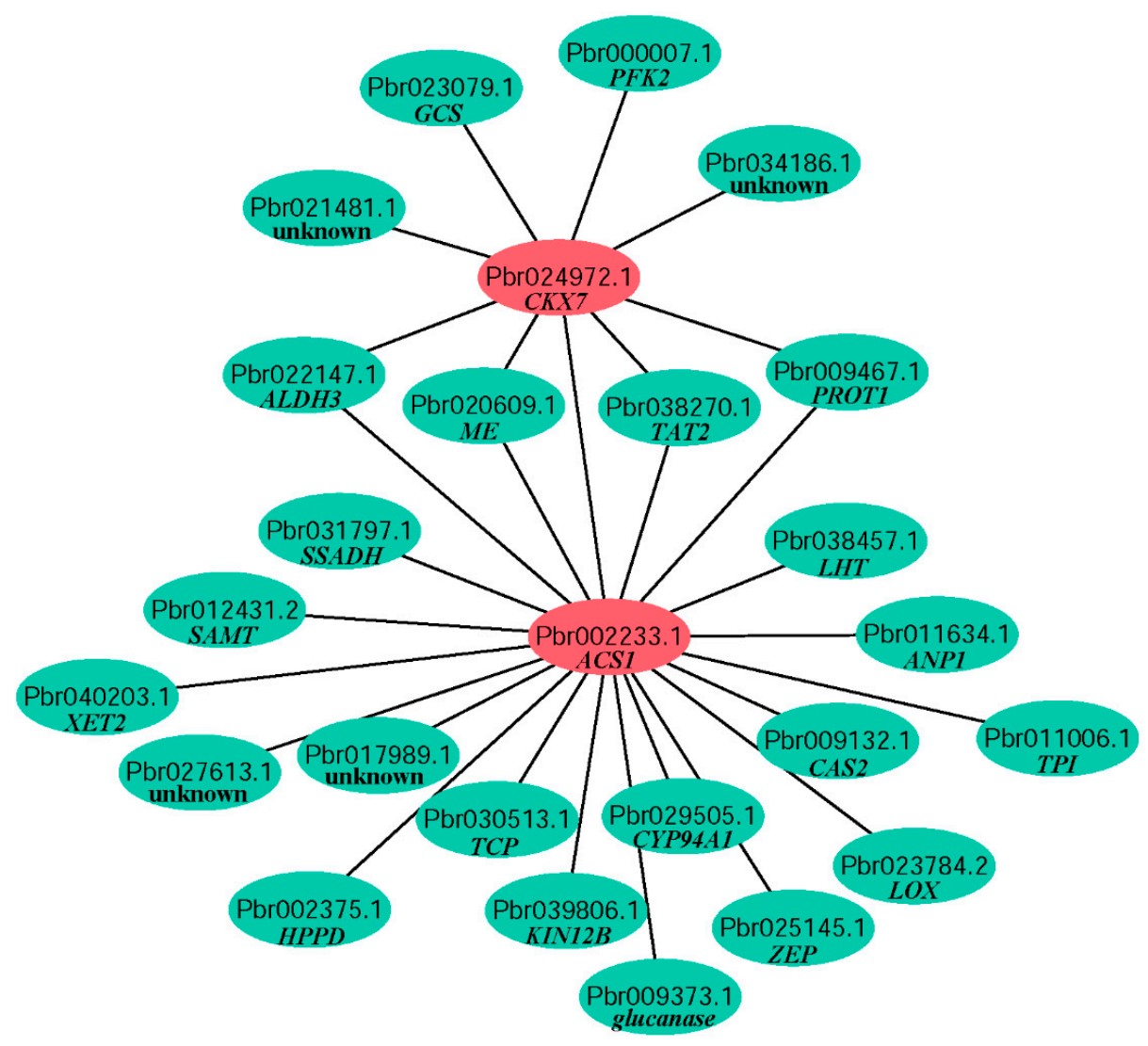

Figure 6. Protein protein interaction of CKX7 and ACS.

\section{Discussion}

In pear breeding, breeders like to choose large fruit cultivars as parents to produce hybrids with big fruits. Therefore, the cultivars with big fruits have already accumulated many genetic loci inducing big fruit by artificial selection [12]. The loci might be different, suggesting that many genes could increase the fruit size. In previous studies, the cell division stage of large fruit pear is longer than that of small fruit pear at the young fruit development. The pear size was mainly related to the cell number, rather than the cell size [11]. The cell division was occurred in the development of young fruit, mostly in forty days after blossom. Therefore, we choose two pear accessions with a consistent phenological period from the hybrids of 'Gold Nijiss Qiki' and 'Housui' to minimize the genetic background differences in this study. The differences of fruit size between 'GH59B' with big fruit and 'GH81S' with small fruit were appeared at 20 DAB and expanded gradually to 30 DAB. The cross-section area of 'GH59B' and 'GH81S' showed that the cell size was enlarged in both of samples, suggesting that the cell size enlargement was one of the factors to increase the fruit weight. The cell size between 'GH59B' and 'GH81S' showed little difference in four stages of fruit development, which proved that the fruit size difference between 'GH59B' and 'GH81S' in young fruit development was induced by cell number. The same results were also found in melon and sweet cherry [6,7].

Since the fruit size was related to the cell division in the early stage of fruit development, the RNA-seq was used to identify the putative important genes in young fruit development. In this study, 797 DEGs were found in the comparison between 'GH59B' and 'GH81S.' A total of eighty-nine DEGs were identified to be related with pear fruit development. Twenty-seven of them were zeatin and gibberellin related genes. Twenty-four of them were other structural genes and thirty-eight of them were transcription factors. Spraying zeatin and gibberellin could increase fruit size in many crop plants, such as apple [29], peach [30] and pepper [31]. Therefore, the KEGG pathways of zeatin, gibberellin and corresponding signal transduction were firstly analyzed to isolate putative key genes. 
Five DEGs were identified. Three DEGs were related to cytokinin including one gene of ZOG1 and two genes of CKX. ZOG inhibited the growth of rice. The overexpression of the $c Z O G 1$ and $c Z O G 2$ genes exhibited short shoot phenotypes, delay of leaf senescence and the decrease in crown root number [32]. $C K X$ is an enzyme that degrades the cytokinin, which negatively regulates plant growth. Reduced expression of $\mathrm{Gn} 1 a$ (OsCKX2) in rice causes cytokinin accumulation in inflorescence meristems and increases the number of reproductive organs, resulting in enhanced grain yield (Ashikari, et al., 2005). In Arabidopsis, ckx3 and ckx5 double mutants form large inflorescences and floral meristems and contain supernumerary ovules, thus leading to an increase in seed set per silique [33]. In this study, the ZOGT1, CKX6 and CKX7 were upregulated at $20 \mathrm{DAB}$ in 'GH81S' and at $30 \mathrm{DAB}$ in 'GH59B', suggesting that the early expression of these genes might terminate the cell division of fruit in 'GH81S.' The Period of cell division in 'GH59B' might be longer than 'GH81S.' Two DEGs were related to gibberellin 2-beta-dioxygenase. Overexpression of the gibberellin 2-oxidase gene causes dwarf phenotypes in Tricyrtis sp. [34] and dwarfism and smaller flowers in Nicotiana tabacum [35]. The expression profile of GA2OX1 and GA2OX8 were consistent with ZOG and CKX in early pear fruit development, implying that these genes might play critical roles in cell division. The size of pear might be related to the temporal expression of these genes. Both of cytokinin and gibberellin might participate in the regulation of fruit development.

Beside cytokinin and gibberellin related genes, some other DEGs were identified. Two types of genes related to ethylene and brassinosteroids might involve in the fruit development. One gene of 1-aminocyclopropane-1-carboxylate synthase (ACS) and three genes of 1-aminocyclopropane-1carboxylate oxidase $(A C O)$ were identified. ACS is a rate-limiting enzyme in ethylene biosynthesis and ACO catalyzes the last step in the biosynthesis of ethylene [36]. In the present study, ACS (Pbr002233.1) and ACO (Pbr023059.1, Pbr031954.1 and Pbr015589.1) were upregulated at 20 DAB in 'GH81S,' suggesting that the ethylene might be synthesized in this period in 'GH81S.' In 'GH59B,' the gene of $A C S$ was always expressed lowly but three genes of $A C O$ were upregulated significantly at $30 \mathrm{DAB}$ in 'GH59B,' implying that the synthesis of ethylene might be delayed in pear with big fruit. Brassinosteroid in shoots is required for fruit development in tomato [37]. Two genes were cytochrome P450 (CYP90A1 and CYP734A1) related to brassinosteroids. CYP90A1 is a brassinosteroid biosynthetic cytochrome P450 in Arabidopsis and catalyzes C-3 oxidation [38]. The CYP734A subfamily has been shown to inactivate brassinosteroid hormones in Arabidopsis and tomato [39]. Plants overexpressing CYP734A1 exhibit severe dwarfism [40]. The expression of CYP734A appears to be up-regulated by exogenous brassinosteroids. In this study, CYP90A1 and CYP734A1 were upregulated at 20 DAB in 'GH81S' and at 30 DAB in 'GH59B.' The expression of CYP734A1 might be regulated by the synthesize of brassinosteroid induced by CYP90A1. The CYP714 family members were reported involved in GA metabolism. The overexpression of CYP714A1 and CYP714A2 in Arabidopsis causes dwarfism [41]. Our result showed that one gene of CYP714A1 (Pbr002890.1) was upregulated at 20 and 30 DAB in 'GH81S', which might prevent the fruit development. One gene of WUSCHEL-related homeobox (WOX1) was identified in 'GH81S' and 'GH59B.' The function of most WOX genes studied so far can be ascribed to the promotion of cell division and/or prevention of premature differentiation [42]. The gene of WOX1 was upregulated in 'GH81S' and 'GH59B' at 10 DAB and then the expression decreased at 20 and $30 \mathrm{DAB}$, suggesting that this gene might promote cell division in the early stage of fruit development.

The transcription factor and protein protein interaction were studied to analyze the regulatory network. Nine $N A C$ transcription factors were isolated in this study. $N A C$ transcription factors FEZ was reported to control the delicately tuned reorientation and timing of cell division in a subset of stem cells in Arabidopsis. It is expressed in root cap stem cells, where it promotes periclinal, root cap-forming cell divisions [43]. JUB1 (NAC) was a transcriptional regulator of GA/BR signaling, JUB1 directly represses the hormone biosynthesis genes GA3OX1 and DWARF4 (CYP90) [44]. In the present work, the expression of nine NAC transcription factors was consistent with GA2OX1 and $C K X 7$, suggesting that these transcription factors might be related with gibberellin and cytokinin. 
$E R F$ family are conservatively widespread in the plant kingdom involved in the control of primary and secondary metabolism, growth and developmental programs [45]. In this study, Four ERF transcription factors were isolated and the expression profile was consistent with $A C O$ and $A C S$, suggesting that the ethylene might modulate fruit cell division. $M Y B$ transcription factors are widely involved in many biological processes, such as the regulation of plant secondary metabolism and the response of hormones and stress [46]. Three $M Y B$ transcription factors were identified in our result and were annotated to MYB7 and MYB8 in Malus. The function of these MYBs was not clear, which might be related with the development of pear fruit. Overexpression of GLKs (GOLDEN2-LIKE) enhances chloroplast development and nutritional quality in tomato [47]. In Pyrus, one gene of GLK2 was upregulated in both of 'GH59B' and 'GH81S,' which might be related with the fruit development. In the PPI network, CKX7 and ACS were found to interact in the fruit development. CKX7 could degrade the cytokinin and ACS improved ethylene biosynthesis, implying that the cytokinin and ethylene co-regulate the fruit development in pear.

In conclusion, this study confirmed that fruit size difference of Pyrus pyrifolia was determined by cell number in young fruit development. To our knowledge, this work is the first study to provide comprehensive sequencing and DEG profiling data for a dynamic view of the transcriptomic variation in pear fruit development. Approximately 797 differentially expressed genes were isolated from the transcriptome in 30 days after blossom, offering new insights into the molecular mechanisms underlying fruit development. Gibberellin and cytokinin related genes were identified that might play important roles in cell division. Our findings provided a relatively complete molecular platform for future studies on the difference of fruit size in pear.

\section{Material and Methods}

\subsection{Plant Materials}

Two pear accessions of 'GH81S' and 'GH59B' were selected at the experimental farm of Shanghai Academy of Agricultural Sciences in Zhuanhang Town (Shanghai, China) and both of them were crosses between 'Gold Nijiss Qiki' (P. pyrifolia) and 'Housui' (P. pyrifolia). The pear trees were 10 years old and considered to be in the adult phase. The phenophase of two pear accessions were similar and the bloom period was in 5 April 2016. We sampled at 10 days after blossom (15 April 2016, 10 DAB), 20 days after blossom (25 April 2016, 20 DAB), 30 days after blossom (5 May 2016, 30 DAB) and 40 days after blossom (15 May 2016, 40 DAB). The mature fruits were collected at 130 days after blossom (15 August 2016, 130 DAB). At each sampling points, eight fruits were collected in one biological replicate and used for RNA extraction. The RNA of three biological replications were pooled by equal quantities ( $5 \mu \mathrm{g} /$ replication) to establish one library. Six libraries in two pear accessions at 10, 20 and $30 \mathrm{DAB}$ were used for RNA-seq.

\subsection{Histological Sections of Young Fruit}

The paraffin sections were used to conduct the histological observation. Fruit samples of 'GH81S' and 'GH59B' were collected at 10, 20, 30, 40 and $130 \mathrm{DAB}$, immediately fixed in formaldehyde-acetic acid-alcohol fixative and stored at $4{ }^{\circ} \mathrm{C}$. The flesh tissue was dehydrated in a graded ethanol series $(70 \%$, $80 \%, 90 \%, 100 \%, 45 \mathrm{~min}$ for each concentration) and cleared with xylene for $1 \mathrm{~h}$ and then embedded in paraffin. The paraffin block was sliced into thin slices by the microtome of Leica RM2265 (Leica, Solms, Germany). The slices were dried and rehydrated on glass substrates and then stained with safranin $(1 \%, w / w)$ for $1 \mathrm{~h}$. After washing with water and ethanol, the slices were stained with fast green $(1 \%$, $w / w)$ for $30 \mathrm{~s}$. The anatomical images were observed using a microscopic imaging system of Eclipse Ti-S (Nikon, Tokyo, Japan). 


\subsection{RNA Extraction and RNA-Seq}

Total RNA was extracted using the CTAB method [48]. RNA purity and concentration were assessed using the NanoDrop 2000 (Thermo, Waltham, MA, USA). Genomic DNA was digested with DNase I. The cDNA libraries were constructed with approximately $5 \mu \mathrm{g}$ of RNA for each sample using the NEBNext Ultra RNA Library Prep Kit (NEB Inc., San Diego, SF, USA) according to the manufacturer's instructions and index codes were added to attribute sequences to each sample. To select cDNA fragments of preferentially 250-300 bp in length, the library fragments were purified using the AMPure XP System (Beckman Coulter, Los Angeles, CA, USA). Subsequently, $3 \mu \mathrm{L}$ of USER Enzyme (NEB) was used with size-selected, adaptor-ligated cDNA at $37^{\circ} \mathrm{C}$ for $15 \mathrm{~min}$. Then PCR (20 $\mu \mathrm{L}$ total volume) was performed using $10 \mu \mathrm{L}$ of Q5 Hot Start HiFi PCR Master Mix (M0543, NEB Inc., San Diego, CA, USA), $1 \mu \mathrm{L}$ of Universal PCR primers, $1 \mu \mathrm{L}$ of Index $(\mathrm{X})$ Primer, $2 \mu \mathrm{L}$ of cDNA and $7 \mu \mathrm{L}$ of RNase-free water. The PCR products were purified (AMPure XP system) and library quality was assessed on the Agilent Bioanalyzer 2100 system (Agilent, Santa Clara, CA, USA). Each library (approximately $10 \mathrm{ng}$ ) was used for Paired-End sequencing using Illumina HiSeq ${ }^{\mathrm{TM}} 4000$ (Illumina, San Diego, CA, USA). Raw sequence data in the FASTQ format were filtered to remove reads containing adaptors, reads with more than $5 \%$ unknown nucleotides and low-quality reads with more than $20 \%$ bases of quality value $\leq 10$. Only clean reads were used in the following analysis. The clean reads data have been deposited in the NCBI Sequence Read Archive (http:/ / www.ncbi.nlm.nih.gov/sra/) and the SRA accession number is SRP150403.

\subsection{Identification of Differentially Expressed Genes (DEGs)}

Clean reads were mapped to the Pyrus reference genome (NCBI, AJSU00000000) using TopHat and cufflinks software (Hopkins, Baltimore, MD, USA), allowing mismatches of no more than two bases. The unique mapped reads were used in subsequent analyses. The gene expression level was calculated using the method of reads per kb per Million reads (RPKM). Baggerly's test and the false discovery rate (FDR) with a significance level of $\leq 0.001$ and the absolute value of $\log _{2}$ Ratio $\geq 1$ were set as the threshold to determine the significance of the gene expression difference. KEGG pathway analysis was performed by first mapping all DEGs (Differential Expressed Genes) to KEGG terms in the database (https:/ / www.genome.jp/ kegg/pathway.html), calculating the gene numbers for every term and subsequently using the hypergeometric test to identify significantly enriched KEGG terms in the input list of DEGs.

\subsection{Expression Analysis of Quantitative Real-Time PCR}

Total RNA was extracted from the fruits at four stages, 10, 20, 30 and $40 \mathrm{DAB}$, using three biological replicates. First-strand cDNA was synthesized from $1 \mu \mathrm{g}$ of total RNA using the PrimerScript RT reagent Kit with gDNA Eraser (RR047, TaKaRa, Osaka, Japan), diluted 10 times with $\mathrm{H}_{2} \mathrm{O}$ and subsequently used as templates for Q-PCR assays. The Q-PCR mixture ( $15 \mu \mathrm{L}$ total volume) contained $7.5 \mu \mathrm{L}$ of SYBR Premix ExTaq (RR820, Takara), $0.5 \mu \mathrm{L}$ of each primer $(10 \mu \mathrm{M}), 2 \mu \mathrm{L}$ of cDNA and $4.5 \mu \mathrm{L}$ of RNase-free water. The reactions were performed on a LightCycler480 instrument (Roche, Basel, Switzerland) according to the manufacturer's instructions. The two-step Q-PCR program was initiated at $95{ }^{\circ} \mathrm{C}$ for $30 \mathrm{~s}$, followed by 40 cycles at $95^{\circ} \mathrm{C}$ for $5 \mathrm{~s}$ and $60^{\circ} \mathrm{C}$ for $20 \mathrm{~s}$. Template-less controls for each primer pair were included in each run. The specificity of the Q-PCR primers was confirmed using a melting curve and the Q-PCR products were sequenced (Table 2). Expression was calculated as $2^{-\Delta \Delta C t}$ and normalized to that of the actin gene (JN684184) [49] and UBI (AF179386) [50] and the data were managed using the Data Processing System (DPS, v. 7.05). 
Table 2. The primers of Q-PCR in present study.

\begin{tabular}{|c|c|c|c|c|c|}
\hline Primer & Sequence & $\operatorname{Tm}\left({ }^{\circ} \mathrm{C}\right)$ & Length $(b p)$ & $\begin{array}{c}\text { Accession } \\
\text { Number }\end{array}$ & $\begin{array}{c}\text { PCR } \\
\text { Efficiency } \%\end{array}$ \\
\hline Q-ZOG1-F & ССАССТСААССААСТССТАСАС & 58.6 & 97 & XM_018648918 & 107 \\
\hline Q-ZOG1-R & CTTAACTTGGCGGTTGTGAGTG & 60.1 & & & \\
\hline Q-GA2OX1-F & GCAGATAACAGGCTTGGACACTT & 60.4 & 123 & XM_009356581.2 & 108 \\
\hline Q-GA2OX1-R & GATTTCCGAGTACCGAGATTGAA & 60.3 & & & \\
\hline Q-CKX7-F & GAGATTTGTGGAGCGGAAGAC & 58.8 & 188 & XM_009336405.2 & 109 \\
\hline Q-CKX7-R & CCAGTAGAAACTAATCAAGCCAATA & 57.7 & & & \\
\hline Q-CKX6-F & AAAATCTGCTTACGACCCСТTGG & 63.8 & 124 & XM_009369812.2 & 96 \\
\hline Q-CKX6-R & ACATGCCTTTAGGGCCTCTTCTT & 62.8 & & & \\
\hline Q-ACS-F & TGTCTCCTCATACACCGATACCC & 60.5 & 171 & XM_009365119.2 & 102 \\
\hline Q-ACS-R & GAAAGAAGGTATCCACCACTCAA & 57.9 & & & \\
\hline Q-ACO-F & TCCCAGTTGTTGACTTGAGCCT & 61.2 & 194 & NM_001302321.1 & 93 \\
\hline Q-ACO-R & САTTTCСТTAAАССТTTGCTCCA & 60.7 & & & \\
\hline Q-NAC25-F & TTCTACССТAATCCTGCACTTCT & 57.3 & 118 & XM_009381159.2 & 108 \\
\hline Q-NAC25-R & САТСТТАААСССАССАТССААА & 59.3 & & & \\
\hline Q-WOX1-F & TGTTACTGGGAGGCGTTTAGATT & 60.2 & 119 & XM_009361806 & 105 \\
\hline Q-WOX1-R & AATACAATGGCGCTTATACAAGTC & 58.1 & & & \\
\hline Q-actin-F & CCATCCAGGCTGTTCTCTC & 54.7 & 139 & JN684184 & 100 \\
\hline Q-actin-R & GCAAGGTCCAGACGAAGG & 55.7 & & & \\
\hline Q-UBI-F & ACCCTCGCCGACTACAAC & 55.3 & 198 & XM_009368893.2 & 94 \\
\hline Q-UBI-R & АСТCСТTCCGCAGCСТCT & 55.4 & & & \\
\hline
\end{tabular}

Supplementary Materials: Supplementary materials can be found at http:/ / www.mdpi.com/1422-0067/19/8/ 2342/s1.

Author Contributions: S.J. and H.A. performed the experiments and wrote the manuscript. X.W., C.S. and F.X. helped to revise the manuscript. J.L. involved in designing the research and revised the manuscript. All authors read and approved the manuscript.

Funding: This work was financed by a Grant for Growth of Young Talents in Agricultural System in Shanghai (2017-1-2), a Grant for Seed Industry Project from the Agricultural Commission of Shanghai (2017-3-2) and a Grant from the National Natural Science Foundation of China (No. 31701886).

Acknowledgments: We would like to thank 1GENE (Hangzhou, China) to provide technical support in our transcriptome analysis.

Conflicts of Interest: The authors declare no conflicts of interest.

\section{References}

1. Hampson, C.; Bedford, K. Efficacy of blossom thinning treatments to reduce fruit set and increase fruit size of Ambrosia and Aurora Golden Gala apples. Can. J. Plant Sci. 2015, 91, 983-990. [CrossRef]

2. Oosthuyse, S.A. Spray application of $\mathrm{KNO}_{3}$, low biuret urea and growth regulators and hormones during and after flowering on fruit retention, fruit size and yield of mango. Acta Hortic. 2015, 135-142. [CrossRef]

3. Canli, F.A.; Pektas, M. Improving fruit size and quality of low yielding and small fruited pear cultivars with benzyladenine and gibberellin applications. Eur. J. Hortic. Sci. 2015, 80, 103-108. [CrossRef]

4. Flaishman, M.A.; Shargal, A.; Shlizerman, L.; Levyadun, S.; Stern, R.A.; Grafi, G. Synthetic cytokinins cppu and $\mathrm{tdz}$ prolong the phase of cell division in developing pear (Pyrus communis L.) fruit. Acta Hortic. 2005, 671, 151-157. [CrossRef]

5. Goffinet, M.C.; Robinson, T.L.; Lakso, A.N. A comparison of 'Empire' apple fruit size and anatomy in unthinned and hand-thinned trees. J. Pomol. Hortic. Sci. 1995, 70, 375-387. [CrossRef]

6. Higashi, K.; Hosoya, K.; Ezura, H. Histological analysis of fruit development between two melon (Cucumis melo 1. reticulatus) genotypes setting a different size of fruit. J. Exp. Bot. 1999, 50, 1593-1597. [CrossRef] 
7. Olmstead, J.W.; Iezzoni, A.F.; Whiting, M.D. Genetic differences in sweet cherry fruit size are determined by cell number and not cell size. Hortscience 2005, 40, 1008.

8. Harada, T.; Kurahashi, W.; Yanai, M.; Wakasa, Y.; Satoh, T. Involvement of cell proliferation and cell enlargement in increasing the fruit size of malus, species. Sci. Hortic. 2005, 105, 447-456. [CrossRef]

9. Malladi, A.; Hirst, P.M. Increase in fruit size of a spontaneous mutant of 'Gala' apple (Malus $\times$ domestica Borkh.) is facilitated by altered cell production and enhanced cell size. J. Exp. Bot. 2010, 61, 3003-3013. [CrossRef] [PubMed]

10. Denne, M. The growth of apple fruitlets and the effect of early thinning on fruit development. Ann. Bot. 1960, 24, 397-406. [CrossRef]

11. Zhang, C.; Tanabe, K.; Wang, S.; Tamura, F.; Yoshida, A.; Matsumoto, K. The impact of cell division and cell enlargement on the evolution of fruit size in Pyrus pyrifolia. Ann. Bot. 2006, 98, 537-543. [CrossRef] [PubMed]

12. Azzi, L.; Deluche, C.; Gevaudant, F.; Frangne, N.; Delmas, F.; Hernould, M.; Chevalier, C. Fruit growth-related genes in tomato. J. Exp. Bot. 2015, 66, 1075-1086. [CrossRef] [PubMed]

13. Tanksley, S.D. The genetic, developmental and molecular bases of fruit size and shape variation in tomato. Plant Cell 2004, 16 (Suppl. 1), S181-S189. [CrossRef] [PubMed]

14. Frary, A.; Nesbitt, T.C.; Frary, A.; Grandillo, S.; van de Knaap, E.; Cong, B.; Liu, J.; Meller, J.; Elber, R.; Alpert, K.; et al. Cloning and transgenic expression of $f w 2.2$ : A quantitative trait locus key to the evolution of tomato fruit. Science 2000, 289, 85-88. [CrossRef] [PubMed]

15. Cong, B.; Liu, J.; Tanksley, S.D. Natural alleles at a tomato fruit size quantitative trait locus differ by heterochronic regulatory mutations. Proc. Natl. Acad. Sci. USA 2002, 99, 13606-13611. [CrossRef] [PubMed]

16. Cong, B.; Barrero, L.; Tanksley, S. Regulatory change in YABBYlike transcription factor led to evolution of extreme fruit size during tomato domestication. Nat. Genet. 2008, 40, 800-804. [CrossRef] [PubMed]

17. Martí, C.; Orzáez, D.; Ellul, P.; Moreno, V.; Carbonell, J.; Granell, A. Silencing of DELLA induces facultative parthenocarpy in tomato fruits. Plant J. 2007, 52, 865-876. [CrossRef] [PubMed]

18. Lenhard, M. Growing up to one's standard. Curr. Opin. Plant Biol. 2007, 10, 63-69.

19. Krizek, B.A. Making bigger plants: Key regulators of final organ size. Curr. Opin. Plant Biol. 2009, 12, 17-22. [CrossRef] [PubMed]

20. Mizukami, Y.; Fischer, R.L. Plant organ size control: Aintegumenta regulates growth and cell numbers during organogenesis. Proc. Natl. Acad. Sci. USA 2000, 97, 942-947. [CrossRef] [PubMed]

21. Hu, Y.; Xie, Q.; Chua, N.H. The Arabidopsis auxin-inducible gene ARGOS controls lateral organ size. Plant Cell 2003, 15, 1951-1961. [CrossRef] [PubMed]

22. Anastasiou, E.; Kenz, S.; Gerstung, M.; MacLean, D.; Timmer, J.; Fleck, C.; Lenhard, M. Control of plant organ size by KLUH/CYP78A5-dependent intercellular signaling. Dev. cell 2007, 13, 843-856. [CrossRef] [PubMed]

23. Carolyn, K.; Ohno, G.; Venugopala, R.; Marcus, G.B.H.; Elliot, M.M. The Arabidopsis JAGGED gene encodes a zinc finger protein thatpromotes leaf tissue development. Development 2004, 131, 1111-1122.

24. Disch, S.; Anastasiou, E.; Sharma, V.K.; Laux, T.; Fletcher, J.C.; Lenhard, M. The E3 ubiquitin ligase big brother controls Arabidopsis organ size in a dosage-dependent manner. Curr. Biol. 2006, 16, 272-279. [CrossRef] [PubMed]

25. Inzé, D.; De, V.L. Cell cycle regulation in plant development. Annu. Rev. 2006, 40, 77-105. [CrossRef] [PubMed]

26. Boudolf, V.; Vlieghe, K.; Beemster, G.T.; Magyar, Z.; Torres Acosta, J.A.; Maes, S.; Van Der Schueren, E.; Inze, D.; De Veylder, L. The plant-specific cyclin-dependent kinase CDKB1;1 and transcription factor E2Fa-DPa control the balance of mitotically dividing and endoreduplicating cells in Arabidopsis. Plant Cell 2004, 16, 2683-2692. [CrossRef] [PubMed]

27. De Veylder, L.; Beeckman, T.; Beemster, G.T.; Krols, L.; Terras, F.; Landrieu, I.; van der Schueren, E.; Maes, S.; Naudts, M.; Inze, D. Functional analysis of cyclin-dependent kinase inhibitors of Arabidopsis. Plant Cell 2001, 13, 1653-1668. [CrossRef] [PubMed]

28. Wu, J.; Wang, Z.; Shi, Z.; Zhang, S.; Ming, R.; Zhu, S.; Khan, M.A.; Tao, S.; Korban, S.S.; Wang, H.; et al. The genome of the pear (Pyrus bretschneideri Rehd.). Genome Res. 2013, 23, 396-408. [CrossRef] [PubMed]

29. Mohammad, M.K.; Amru, N.B.; Normaniza, O.; Faruq, G.; Rahman, M.R.; Mohd, S.A. Fruit development, pigmentation and biochemical properties of wax apple as affected by localized application of ga3 under field conditions. Braz. Arch. Biol. Technol. 2013, 56, 11-20. 
30. Singh, Z.; Grewal, G.P.S.; Singh, L.; Müller, W.; Polesny, F.; Verheyden, C. Gibberellin a4/a7 improved fruit set, retention, yield and quality of subtropical peach (Prunus persica batsch.). Acta Hortic. 2000, 525, 467-472. [CrossRef]

31. Honda, I.; Matsunaga, H.; Kikuchi, K.; Matuo, S.; Fukuda, M.; Imanishi, S. Involvement of cytokinins, 3-indoleacetic acid and gibberellins in early fruit growth in pepper (Capsicum annuum L.). Hortic. J. 2016, 86, 52-60. [CrossRef]

32. Kudo, T.; Makita, N.; Kojima, M.; Tokunaga, H.; Sakakibara, H. Cytokinin activity of cis-zeatin and phenotypic alterations induced by overexpression of putative cis-Zeatin-O-glucosyltransferase in rice. Plant Physiol. 2012, 160, 319-331. [CrossRef] [PubMed]

33. Bartrina, I.; Otto, E.; Strnad, M.; Werner, T.; Schmulling, T. Cytokinin regulates the activity of reproductive meristems, flower organ size, ovule formation and thus seed yield in Arabidopsis thaliana. Plant Cell 2011, 23, 69-80. [CrossRef] [PubMed]

34. Otani, M.; Meguro, S.; Gondaira, H.; Hayashi, M.; Saito, M.; Han, D.S.; Inthima, P.; Supaibulwatana, K.; Mori, S.; Jikumaru, Y.; et al. Overexpression of the gibberellin 2-oxidase gene from Torenia fournieri induces dwarf phenotypes in the liliaceous monocotyledon Tricyrtis sp. J. Plant Physiol. 2013, 170, 1416-1423. [CrossRef] [PubMed]

35. Xiao, Z.; Fu, R.; Li, J.; Fan, Z.; Yin, H. Overexpression of the gibberellin 2-oxidase gene from camellia lipoensis, induces dwarfism and smaller flowers in Nicotiana tabacum. Plant Mol. Biol. Rep. 2016, 34, 182-191. [CrossRef]

36. Hamilton, A.J.; Bouzayen, M.; Grierson, D. Identification of a tomato gene for the ethylene-forming enzyme by expression in yeast. Proc. Natl. Acad. Sci. USA 1991, 88, 7434-7437. [CrossRef] [PubMed]

37. Lisso, J.; Altmann, T.; Mussig, C. Metabolic changes in fruits of the tomato dx mutant. Phytochemistry 2006, 67, 2232-2238. [CrossRef] [PubMed]

38. Ohnishi, T.; Godza, B.; Watanabe, B.; Fujioka, S.; Hategan, L.; Ide, K.; Shibata, K.; Yokota, T.; Szekeres, M.; Mizutani, M. CYP90A1/CPD, a brassinosteroid biosynthetic cytochrome P450 of Arabidopsis, catalyzes C.-3 oxidation. J. Biol. Chem. 2012, 287, 31551-31560. [CrossRef] [PubMed]

39. Neff, M.M.; Nguyen, S.M.; Malancharuvil, E.J.; Fujioka, S.; Noguchi, T.; Seto, H.; Tsubuki, M.; Honda, T.; Takatsuto, S.; Yoshida, S.; et al. BAS1: A gene regulating brassinosteroid levels and light responsiveness in Arabidopsis. Proc. Natl. Acad. Sci. USA 1999, 96, 15316-15323. [CrossRef] [PubMed]

40. Thornton, L.E.; Peng, H.; Neff, M.M. Rice CYP734A cytochrome P450s inactivate brassinosteroids in Arabidopsis. Planta 2011, 234, 1151-1162. [CrossRef] [PubMed]

41. Magome, H.; Nomura, T.; Hanada, A.; Takeda-Kamiya, N.; Ohnishi, T.; Shinma, Y.; Katsumata, T.; Kawaide, H.; Kamiya, Y.; Yamaguchi, S. CYP714B1 and CYP714B2 encode gibberellin 13-oxidases that reduce gibberellin activity in rice. Proc. Natl. Acad. Sci. USA 2013, 110, 1947-1952. [CrossRef] [PubMed]

42. Van der Graaff, E.; Laux, T.; Rensing, S.A. The WUS homeobox-containing (WOX) protein family. Genome Biol. 2009, 10, 248. [CrossRef] [PubMed]

43. Willemsen, V.; Bauch, M.; Bennett, T.; Campilho, A.; Wolkenfelt, H.; Xu, J.; Haseloff, J.; Scheres, B. The NAC domain transcription factors FEZ and SOMBRERO control the orientation of cell division plane in Arabidopsis root stem cells. Dev. Cell 2008, 15, 913-922. [CrossRef] [PubMed]

44. Shahnejat-Bushehri, S.; Tarkowska, D.; Sakuraba, Y.; Balazadeh, S. Arabidopsis NAC transcription factor JUB1 regulates GA/BR metabolism and signalling. Nat. Plants 2016, 2, 16013. [CrossRef] [PubMed]

45. Licausi, F.; Ohme-Takagi, M.; Perata, P. APETALA2/Ethylene Responsive Factor (AP2/ERF) transcription factors: Mediators of stress responses and developmental programs. New Phytol. 2013, 199, 639-649. [CrossRef] [PubMed]

46. Cheng, H.; Song, S.; Xiao, L.; Soo, H.M.; Cheng, Z.; Xie, D. Gibberellin acts through jasmonate to control the expression of myb21, myb24 and myb57 to promote stamen filament growth in Arabidopsis. PLoS Genet. 2009, 5, e1000440. [CrossRef] [PubMed]

47. Nguyen, C.V.; Vrebalov, J.T.; Gapper, N.E.; Zheng, Y.; Zhong, S.; Fei, Z.; Giovannoni, J.J. Tomato golden2-like transcription factors reveal molecular gradients that function during fruit development and ripening. Plant Cell 2014, 26, 585-601. [CrossRef] [PubMed]

48. Chang, S.; Puryear, J.; Cairney, J. A simple and efficient method for isolating RNA from pine trees. Plant Mol. Biol. Rep. 1993, 11, 113-116. [CrossRef] 
49. Bai, S.; Sun, Y.; Qian, M.; Yang, F.; Ni, J.; Tao, R.; Li, L.; Shu, Q.; Zhang, D.; Teng, Y. Transcriptome analysis of bagging-treated red Chinese sand pear peels reveals light-responsive pathway functions in anthocyanin accumulation. Sci. Rep. 2017, 7, 63. [CrossRef] [PubMed]

50. Xu, Y.; Hui, L.; Li, X.; Jing, L.; Wang, Z.; Yang, Q.; Chang, Y. Systematic selection and validation of appropriate reference genes for gene expression studies by quantitative real-time PCR in pear. Acta Physiol. Plant. 2015, 37, 40. [CrossRef]

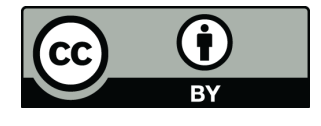

(C) 2018 by the authors. Licensee MDPI, Basel, Switzerland. This article is an open access article distributed under the terms and conditions of the Creative Commons Attribution (CC BY) license (http://creativecommons.org/licenses/by/4.0/). 